\title{
Child sexual abuse-children and families referred to a treatment project and the effects of intervention
}

\author{
ARNON BENTOVIM, PAULA BOSTON, ANNEMARIE VAN ELBURG
}

\begin{abstract}
The characteristics of a series of $\mathbf{2 7 4}$ families who were referred to a sexual abuse treatment programme were analysed. Information was obtained on 411 abused children and 362 non-abused children. Different forms of sexual abuse were noted, with $77 \%$ of girls and $23 \%$ of boys affected. Boys tended to be abused at a younger age, more severely, and for longer periods than girls. There was a predominance of lower social class groups among the parents, and a wide variety of family structures, with reasonable stability over time. Ninety six per cent of perpetrators were men, and biological and step-parents predominated. Contributing factors in both the family history and the current perpetrators and their wives included sexual abuse, violence, chaotic families, marital problems, sexual difficulties, alcoholism, and subnormality.

Follow up of 120 families, 180 victims, and 226 siblings showed that prosecution occurred in $60 \%$ of cases, with a high percentage of perpetrators being imprisoned. Treatment was offered to $87 \%$ of families, but because the treatment programme was in the early stages of development a variable number of children and parents were offered family treatment or treatment in groups for parents and children separately. There was an improvement in the victim's circumstances in $61 \%$ of cases, and a noticeable
\end{abstract}

\footnotetext{
Department of Psychological Medicine, Hospital for Sick Children, London WC1N 3JH

ARNON BENTOVIM, MB, FRCPSYCH, consultant psychiatrist

PAULA BOSTON, LSW, research assistant

ANNEMARIE VAN ELBURG, $M D$, research assistant

Correspondence to: Dr Bentovim.
}

reduction in "sexualised" and general emotional difficulties among victims, but there was a reabuse rate of $16 \%$. Protection of children was achieved through changes of family attitude and changes in family structure including divorce and separation: $14 \%$ of victims were rehabilitated to both parents, $33 \%$ to mothers only, and $26 \%$ to new families or other residences. Consensus in the family that abuse had occurred was seen as an important factor in determining which children could be rehabilitated with both their parents, with their mothers only, or with new families; which families could be offered or accepted treatment; and whether positive changes in the family occurred.

\section{Introduction}

A survey of sexually abused children who were referred to professionals during 1978 and 1979 showed that three quarters had been abused within the family rather than by strangers. ${ }^{1}$ Children of both sexes and all ages were abused.

The common response to child sexual abuse was imprisonment of perpetrators and reception of children into care. A serious intrafamilial form of child abuse was being dealt with not by therapeutic approaches but punitively, the child being "rescuea" and the families disrupted.

In 1981 a child sexual abuse treatment project was set up in this department, and by the middle of 1987 over 650 cases had been referred, the number of cases doubling each year. An analysis of the first 56 cases indicated that a therapeutic programme could be developed that attempted to meet the needs of all members of the family through a combination of group and family work. ${ }^{2}$

The aims of treatment are:

(1) To limit the physical and emotional damage to the child and improve the child's emotional functioning. This is done by helping children to understand what has happened to them and teaching them skills to prevent recurrence, as well as working to help the 
child to deal with traumatic experiences. Such work is best carried out in groups of children of similar ages. ${ }^{3}$

(2) To ensure that children are protected from further abuseinitially by ensuring that the child and perpetrator live separately. This allows the family's capacity for child care to be assessed in a legal framework. Alternative care in foster families is provided if necessary. Such work is carried out closely in liaison with community social workers.

(3) To make changes in the family structure that contributed to the sexual abuse of the child by working on marital and family relationships to improve functioning for all members of the family. If the child cannot be fully integrated into the family a place may need to be sought in a new family. Work is carried out in part in groups of parents working together where rehabilitation seems a possibility or in groups of mothers who are working towards being able to cope without a partner. There are also regular meetings with family and community professionals to review and evaluate progress.

We report a survey of families referred to the treatment programme and their follow up.

\section{Characteristics of sexually abused children and their families referred to the sexual abuse project}

\section{METHODS}

The study was based on 274 families referred to the sexual abuse project at this hospital between 1981 and the middle of 1986. Information was gathered retrospectively for the first half of the cases by abstracting information from case files. For the second half information was obtained prospectively by sending out a detailed questionnaire to referral agencies. We thus had information on 411 abused children and their 362 non-abused siblings from the 274 families. Comparison of cases collected retrospectively and prospectively showed no appreciable bias in findings, so that the group is treated as a whole to describe the characteristics of families referred.

\section{RESULTS}

\section{Reasons for referral and patterns of abuse-boys and girls}

In line with the referral policy $78 \%$ of the families had been referred by social services departments to the hospital. The professionals who referred them were convinced that abuse had occurred or that there was a high index of suspicion.

The most frequent form of abuse described was inappropriate fondling, either possibly or probably present in $178(65 \%)$ of the children in the 274 families, masturbation of adults in $80(29 \%)$, partial sexual intercourse in $79(28 \%)$, full intercourse in $62(23 \%)$, and anal intercourse in $49(18 \%)$. This last figure represents over half $(53 \%)$ of sexual abuse of the boys who were referred.

Comparison of the sex of children between 411 victims and their 362 non-victim siblings showed that girl victims predominated over boys: $317(77 \%)$ to 94 (23\%). Among the non-victim siblings boys predominated over girls to some degree: $202(57 \%)$ to $151(43 \%)$.

When the age of onset was known (290 children) cases were evenly distributed in groups aged 3-5 years: $66(23 \%)$; 6-8 years: 70 $(24 \%)$; 9-11 years: $66(23 \%)$; and $12-14$ years: $64(22 \%)$. Fourteen $(5 \%)$ of the children were under 3 , and $10(3 \%)$ were 15 or 16 . The boys who were abused tended to be abused initially when under 12 , while girls were abused at any age and throughout adolescence. One hundred and six (44\%) of the known cases were abused for less than 12 months, and over half the known cases $(130,56 \%)$ for a year or longer. Abuse continued for as long as five years or more in 48 cases (20\%).

When the duration of abuse of girls and boys was compared (table I) the findings showed that boys were abused for longer periods than girls. The various forms of abuse were suffered by many children in an increasingly severe form, culminating in vaginal or anal intercourse. An analysis (table II) that graded the degree showed that 301 (78\%) children had more serious forms of
TABLE I-Duration of abuse by sex of victims *

\begin{tabular}{|c|c|c|c|}
\hline Duration (years) & $\begin{array}{l}\text { No (\%) of girls } \\
\quad(n=198)\end{array}$ & $\begin{array}{c}\text { No (\%) of boys } \\
\quad(n=43)\end{array}$ & Total $(n=241)$ \\
\hline $\begin{array}{l}1-3 \\
4-5 \\
6-8\end{array}$ & $\begin{array}{l}92(46) \\
63(32) \\
43(22)\end{array}$ & $\begin{array}{c}14(32 \cdot 5) \\
24(56) \\
5(11 \cdot 6)\end{array}$ & $\begin{array}{r}106(44) \\
87(36) \\
48(20)\end{array}$ \\
\hline \multicolumn{4}{|c|}{$p=0.01$} \\
\hline
\end{tabular}

^Excludes 170 children where duration of abuse was not known.

TABLE II-Degree of sexual abuse by sex of the victim *

\begin{tabular}{|c|c|c|c|}
\hline Degree & $\begin{array}{l}\text { No (\%) of girls } \\
\quad(n=297)\end{array}$ & $\begin{array}{c}\text { No }(\%) \text { of boys } \\
(n=89)\end{array}$ & Total $(n=386)$ \\
\hline $\begin{array}{l}\text { Severe† } \\
\text { Very severe‡ }\end{array}$ & $\begin{array}{l}72(24) \\
225(76) \\
\text { Level of sig }\end{array}$ & $\begin{array}{r}13(15) \\
76(85) \\
\text { Ince } 0.1\end{array}$ & $\begin{array}{r}85(22) \\
301(78)\end{array}$ \\
\hline
\end{tabular}

$\star$ Excludes 25 cases where the degree of abuse was not known.

Includes exhibitionism, child forced to watch explicit sexual behaviour, inspection of genitals, fondling, adult masturbation.

$\ddagger$ Includes oral-genital contact, partial sexual intercourse, full sexual intercourse, anal intercourse.

abuse. There was a trend for boys to be more severely abused than girls: $76(85 \%)$ boys compared with $225(76 \%)$ girls.

The average family size of 2.8 is above the national average, and there were some very large sibships among the families referred. Of the perpetrators, $202(75 \%)$ were household members, parents being the predominant abusers in $127(46 \%)$ of the cases, followed by step-parents $(75,27 \%)$ and then smaller numbers of other relatives, friends of the household, or occasional visitors. There were $264(96 \%)$ men and five (2\%) women. The remaining five (2\%) were accounted for by a small number of multiple abusers, where both mothers and fathers were involved. A few perpetrators were over 60 or under 20 . Most known abusers were between 21 and 60 , representing an appreciable age difference between perpetrator and victim.

In 179 (65\%) families there was one victim only, but in $64(23 \%)$ families there were two and in $31(12 \%)$ families three to five victims. These figures are probably an underestimate as the information was obtained through referral agencies, so that the children who were shown to be abused during treatment are not represented here. Thus it is important to assess all children in a family in which one child has been abused.

When only one child in the family was abused this was most likely to be a girl (153 (85\%) girls compared with 26 (15\%) boys). In general, first born children seemed to be more at risk-and these were more likely to be girls - than subsequent children in the family who were abused. There were substantially more households in which the victims were girls $(199,73 \%)$ than either mixed-that is, boys and girls $(44,16 \%)-$ or boys only $(31,11 \%)$. It seems that when one girl in a family is abused other girls in the household are at risk. It is also possible that when girls are abused in the family then boys may be abused rather than boys being the focus of abuse alone.

Family structure and characteristics of perpetrators and other family members

Of the 274 families, 106 (39\%) were nuclear families-that is, biological or adopted families and children-and 64 (23\%) were stepfamilies. There was a smaller proportion of single parents who had been divorced $(34,12 \%)$ and of cohabitation and common law families $(30,11 \%)$ and a smaller number of single parents, of unmarried members of extended families in the same household, and of foster families $(11,4 \%)$. Although there was a wide variety of family structures, more than $156(57 \%)$ of the families had been together for five or more years and over a quarter $(81,99 \%)$ of the families had been together for more than 10 years. Thus despite the 
varied family types there was a degree of stability of family membership.

Among the 540 adults whose employment was known to referral agencies (321 adults), the predominance of employment category was manual, partially or unskilled occupations, for $174(55 \%)$, or economically inactive, housewives, students, or never worked for $107(30 \%)$. Thus fewer than $47(15 \%)$ of the families referred were in the higher clerical or professional occupational category. A total of $486(90 \%)$ adults had been born in Britain, and $486(90 \%)$ were white.

Referral agents were asked to report on factors related to the adults living in the family that possibly contributed to sexual abuse. The information is variable as it was not collected by direct interview with perpetrators and family members. Sixty two $(10 \%)$ of the total group of adults described having been sexually abused as children, representing abuse in $54(20 \%)$ families. In $14(5 \%)$ families perpetrators only were abused, and in $32(12 \%)$ other adults in the family (in eight (3\%) families both parents). Ninety four (34\%) parents reported that they had lived in families described as being chaotic in functioning. In 52 (19\%) families there was a history of violence in the original family, and a criminal record in 26 $(10 \%)$. These must be seen as an underestimate because families in treatment reveal a far higher incidence of traumatic experiences.

Fifty two (19\%) perpetrators were reported to have abused alcohol, $73(37 \%)$ to have used violence, and $60(22 \%)$ to have unemployment problems. Marital problems were reported by 13 $(48 \%)$ and sexual problems by $102(47 \%)$. The incidence of subnormality was $14(5 \%)$. For the other adult in the household, usually the mother, there was recent or long term physical illness in $32(14 \%)$, psychiatric disorder in $34(14 \%)$, violence towards them in $54(34 \%)$, marital problems reported in $130(63 \%)$, sexual problems in $72(32 \%)$, and subnormality in eight (4\%). Again these figures are an underestimate.

\section{Effects of intervention}

\section{METHODS}

To assess the effects of intervention a follow up study was carried out in 1986 on 120 families who had been referred between 1980 and 1984 with 180 victims and 226 siblings. Follow up was carried out by structured interview with community professionals who had worked with the family, a review of case notes, and an interview with the professionals who worked with the families in our department in the hospital.

Thus the length of follow up was variable for the study presented here and most of the 120 families are represented in the original group of 247 families. Not surprisingly, the way in which they were managed by the community was closely similar to the way in which professionals managed cases as reported in the professional survey of 1978 and $1979 .{ }^{1}$

Seventy three $(61 \%)$ of the perpetrators in the 120 families came to trial, and of that group, $48(66 \%)$ were found guilty and received a prison sentence, seven $(10 \%)$ were given probation, $10(14 \%)$ were given a suspended sentence, and six $(8 \%)$ were acquitted. Prison sentences were lengthy: four (8\%) less than year, $20(42 \%)$ one to two years, and $15(31 \%)$ three to five years. Sentences were often reduced by men being released on parole. The treatment team could contribute to this process by stating that a place would be available in a group at a particular time or by offering to have family meetings either in prison or having the prisoner brought to the hospital.

Most families who were referred were receiving support from social services departments or probation agencies. Treatment was offered in addition, but in the early years of the project not all families could be offered all the treatments now offered. So just under half (55) of the 120 families completed a course of family treatment, and a further third (43) attended some sessions. Family sessions were conducted jointly with community social workers or probation officers and occasionally in prison but usually in the hospital, with a father brought from prison if necessary. Such meetings took place every four to six weeks over 12 to 15 months- that is, between five and 10 meetings were held-and they focused on the responsibility for abuse and the changes needed for families to become protective and how to achieve this.

About half (84) of the 180 victims participated in and completed children's groups, and a further quarter (48) attended some group meetings. Groups for children and adolescents were conducted with five to eight members. Children under age 10 were in mixed groups of boys and girls for weekly sessions over six weeks, and adolescent children were in separate groups for boys and girls for between 12 and 15 weeks. Groups were structured and were planned to help children understand what had happened to them, to cope with traumatic effects, and to learn self protective skills.

Eighteen (10\%) had some individual treatment-weekly psychotherapeutic sessions lasting from three months to a year. Twelve $(10 \%)$ of the couples attended parents' groups, and 35 (9\%) parents attended separate mothers' or fathers' groups. Parents' groups took place in parallel to children's groups so that on treatment evenings up to seven groups might be meeting at the same time, representing members of 15 to 20 families. They also continued for 12 to 15 weeks, some children and parents coming to more than one course of treatment. The focus of these structured groups were the personal, marital, and family issues that led to abuse or failure to protect children and how they could be remedied. Family meetings during group work helped to integrate group experiences.

Children in the families were protected by care orders, wardship, or supervision orders to ensure that attendance for treatment could be maintained. Fathers who had received suspended sentences or probation orders or were on parole from prison attended groups and family treatment as part of an agreement made with their partners; mothers attended as part of a treatment plan worked out in coordination with social services departments.

We were interested to know what happened to the families after intervention, whether the children were protected and whether abuse had recurred, whether there were traumatic signs present or emotional symptoms or sexualised behaviour, and whether there had been any appreciable change in the family's ability to protect. The social workers thought that there had been an overall improvement in the victim's circumstances when this was known at follow up in $110(61 \%)$ of the cases. For $43(24 \%)$ they thought that the situation had not changed and for $18(10 \%)$ that it was worse. This is reflected in the fact that in $83(69 \%)$ children there was no reabuse. A proportion of the children were reabused $(19,16 \%)$, and in a further $18(15 \%)$ it was not clear whether there was reabuse.

\section{Placement of the child and family situation}

The placement of the victims and the non-victimised siblings was examined at follow up (table III). Although a third (77, 34\%) of the

TABLE III-What happened to the children

\begin{tabular}{lccccc}
\hline & \multicolumn{2}{c}{ Victims $(\mathrm{n}=180)$} & & \multicolumn{2}{c}{ Siblings $(\mathrm{n}=226)$} \\
\cline { 2 - 3 } \cline { 5 - 6 } \cline { 5 - 6 } & No & $\%$ & & No & $\%$ \\
\hline With both parents & 25 & 14 & & 76 & 34 \\
With mother only & 59 & 33 & & 74 & 33 \\
With father only & 9 & 5 & & 11 & 5 \\
With relatives only & 2 & 1 & & 2 & 1 \\
With foster parents & 18 & 10 & & 14 & 6 \\
Shared & 31 & 17 & & 7 & 3 \\
Independent & 36 & 20 & & 42 & 19 \\
\hline
\end{tabular}

siblings were with both their parents, only 25 (14\%) of the victims were living with both parents. A third of both victims $(59,33 \%)$ and siblings $(75,33 \%)$ were living with their mothers only, whereas 49 $(27 \%)$ of the victims were living with foster parents or in shared residential care compared with $21(9 \%)$ of the siblings. The membership of the household had clearly changed considerably after abuse was discovered. 
Marital state changed in $60(50 \%)$ of the families: $22(18 \%)$ had separated and $36(30 \%)$ had filed for divorce (although perhaps as a sign of their commitment to protect the child or children). Several couples who were cohabiting married in the follow up period. About a quarter $(32,27 \%)$ of the perpetrators remained at home after the discovery of abuse, and as it was considered that a period of separation and appropriate treatment was needed or a child would be at risk by remaining at home with the perpetrator this would account for the very high number of children who were not living with the original family. After serving their prison sentence a

TABLE IV-Household consensus on whether abuse occurred

\begin{tabular}{lrrrrrr}
\hline & \multicolumn{2}{c}{ At referral } & & \multicolumn{2}{c}{ At follow up } \\
\cline { 2 - 3 } \cline { 5 - 7 } & No & $\%$ & & No & $\%$ \\
\hline Abuse has occurred & 117 & 43 & & 76 & 63 \\
Abuse has not occurred & 32 & 12 & & 19 & 16 \\
Household is divided on the incident & 74 & 27 & & 24 & 20 \\
Not known & 51 & 19 & & 1 & 1 \\
\hline
\end{tabular}

inappropriately adult way to other children or to adults by, for example, playing in an overtly sexual way or touching an adult's genitals-and $(b)$ emotional disturbance and behavioural problems. This takes many forms and relates to elements of post-traumatic stress disorder. ${ }^{5}$ Thus symptoms can range from conduct disorders to emotional difficulties, school anxieties, and school failure to regressive behaviour-for example, wetting and soiling.

Referral agencies were asked for evidence of such behaviours initially and at follow up (table V). There was a considerable change during the follow up period for the degree of sexualised behaviour or emotional disturbance and problems in the victimised children compared with non-victimised siblings. Siblings were less disturbed at referral, and they showed less sexualised behaviour at follow up. There was still a noticeable degree of slight or moderate sexualised behaviour at follow up and a considerable number of children who showed evidence of moderate emotional disturbance and behavioural problems. Given these patterns of behaviour it is perhaps not surprising that reabuse occurred as described earlier. It was not always the perpetrator who reabused the child as a child whose behaviour is sexualised is at risk from others in the environment. It is a clinical impression that where children were

TABLE V-Sexualised behaviour and emotional disturbance or behavioural problems at intake and follow up

\begin{tabular}{|c|c|c|c|c|}
\hline & \multicolumn{2}{|c|}{ No (\%) of victimised children } & \multicolumn{2}{|c|}{ No (\%) of non-victimised children (siblings) } \\
\hline & Intake & Follow up & Intake & Follow up \\
\hline \multicolumn{5}{|c|}{ Sexualised behaviour: } \\
\hline No signs & $162(39)$ & $131(73)$ & $151(42)$ & $196(87)$ \\
\hline Slight/moderate & 53 (13) & 34 (19) & 10 (3) & - \\
\hline Definite/serious & $102(25)$ & 4 (2) & 7 (2) & $1 \quad(1)$ \\
\hline Not known & $94(23)$ & $11 \quad(6)$ & $194(53)$ & 29 (12) \\
\hline Total & $411(100)$ & $180(100)$ & $362(100)$ & $226(100)$ \\
\hline \multicolumn{5}{|c|}{ Emotional disturbance or behavioural problem: } \\
\hline No signs & $36 \quad(9)$ & $78(43)$ & $105(29)$ & $132(58)$ \\
\hline Slight/moderate & $122(30)$ & $72(40)$ & 51 (14) & $45(20)$ \\
\hline Definite/serious & 180 (44) & $16 \quad(9)$ & 39 (11) & 17 (8) \\
\hline Not known & 73 (17) & $14(8)$ & $167(46)$ & 32 (14) \\
\hline Total & $411(100)$ & $180(100)$ & $362(100)$ & $226(100)$ \\
\hline
\end{tabular}

further $18(15 \%)$ perpetrators returned home, and $43(37 \%)$ had left home after the abuse was discovered or did not return home after imprisonment. This may account for the one third of children, both victims and siblings, who were living with their mothers only. The $18(15 \%)$ perpetrators who returned home after prison would have included the fathers who were able to use the treatment facilities offered.

Table IV shows the effect of the degree of acceptance that abuse had occurred and its influence on where children were living at follow up and how the household was constituted. At referral fewer than half of the households (117) had a consensus between all family members that abuse had occurred, whereas at follow up $76(63 \%)$ had achieved such a consensus. This change may have occurred because members of the household who did not believe that abuse had occurred had left, or because, through therapeutic or professional intervention, more family members had come to believe that the child had been abused. Where there was household consensus that sexual abuse had occurred there was a great difference in terms of willingness to attend a complete course of family treatment. Where there was a belief that the abuse had not occurred or the household was divided on this there was a great tendency for families to refuse treatment or drop out, and there was a trend for family members to drop out of groups when there was a lack of consensus or a denial that abuse had occurred. In such cases children would require placement in a foster home or residence if they were thought to be at risk.

\section{Effects of intervention on victims and non-victim siblings}

The two major effects of sexual abuse that have been described are $(a)$ the sexualisation of behaviour-that is, behaving in an reabused there was quite explicit and clear communication by them to professionals that abuse had recurred, and they tried not to allow abuse to continue.

Thus there was some evidence that the children were able to be more assertive, which is one of the aims of the group. In some cases mothers took appropriate action to protect children from reabuse, and in one case a perpetrator admitted to the group that he was still abusing his daughter and then went to the police.

A clinical assessment was made of the degree of family change achieved at follow up. It was thought that in $84(70 \%)$ cases there was a structural change that represented an improvement from the original family context in which abuse had arisen. Only those families who remained in treatment showed the extensive changes that are the aim of treatment, while families who refused such treatment or dropped out were more likely to be seen as worse or to show no change. These findings must be treated cautiously because they were clinical ratings of families through the eyes of the professionals who knew them rather than through direct observations and interviews with family members themselves.

\section{Discussion}

During the first years of a treatment project with a newly recognised form of child abuse the cases referred will be known to other agencies, particularly to social services departments. The large number of families in the occupational categories manual, unskilled, or not working does not conform with the picture of abuse and social class as described in epidemiological studies. ${ }^{6}$ Higher clerical and managerial groups may be dealt with differently -for example, by the use of medical confidentiality or referral to private agencies. Furthermore, the fact that there may be less 
contact between them and social workers may lead to lower suspicion of sexual abuse observed through inappropriate patterns of behaviour in the children.

Perpetrators of abuse are predominantly men, and there are a considerable number of stepfathers as well as fathers. But although family structures are variable, there is a surprising degree of stability in how long the family units have been together. From the little information available there is also evidence that in these families, as shown in other forms of abuse, ${ }^{78}$ the perpetrators and mothers had had a considerable experience of chaotic and violent abusive experiences during childhood and many factors, such as sexual problems, marital difficulties, the use of alcohol, violence, physical illness, and subnormality, may represent the preconditions for a child being sexually abused in a family and the abuse being carried on for long periods and to a severe degree.

It may be seen that when treatment is offered in addition to the prosecution and care that were the typical responses to sexual abuse an improvement is noted for the victims of abuse. Such changes are brought about in part through a change in family structure, by protective action that may remove a child and give a new family context, or by criminal action that will remove the perpetrator, and in part by the therapeutic work offered. What role each of these interventions has is of course difficult to determine.

Community social workers viewed therapeutic work with some enthusiasm. This may indicate that offering a service to a statutory agency may help them to provide services with the necessary intensity and concern, given the extensive disturbance shown by these children and the severity of the family problems. They also recognised the value of structural changes in the family. Living in a context where it is accepted that a child has been abused and therefore requires appropriate protection and re-education is itself an important factor. Intervention can make a situation worse for a family; change can be limited or more intrusive. Change in the family structure is very striking in comparison to the relative stability previously. It has been reported that long term sexual abuse of a child may maintain the togetherness of a family, where there may be characteristics indicative of high levels of violence, use of alcohol, or major sexual and marital problems that might otherwise lead to separation. ${ }^{9}$ It may be that improvement for a child by separating it from an abusing parent, or from unprotective parents who cannot change, is the most appropriate and effective form of intervention.

As the number of younger children being referred for possible abuse grows the penalties for taking responsibility for abuse are high in terms of possible sentencing and public humiliation. The fear of family breakdown, which is characteristic of so many of these families, may serve to maintain secrecy and seriously deter them from openly acknowledging that abuse has occurred.
Consensus about whether abuse had occurred in the household seems to be an important factor in determining the future and outcome-for example, whether the couple remains together and whether the perpetrator remains at home or returns home after prison or leaves. It also seems to indicate whether treatment will be accepted or refused and whether children who are victims will return to both their parents or to the one parent who believes what has happened.

If therapeutic work was offered in a statutory context without punitiveness, using probation orders combined with treatment orders, ${ }^{10}$ it would be interesting to see whether more perpetrators would accept responsibility for abuse and more families arrive at consensus that abuse had occurred. More victims would be rehabilitated to their families rather than experience the double victimisation of abuse and rejection by their families which their siblings do not.

We thank the Joint Research Boards of the Hospital for Sick Children and the Institute of Family Therapy (London) for financial support (PB) and the Family Studies Fund of the Hospital for Sick Children for support (AVE). We thank Marjorie Smith, Academic Department of Child Psychiatry, Institute of Child Health, for statistical advice and questionnaire design; Alan Hume, University of London Computer Centre, for computational advice; Betty Ann Smith and Esther La Plane for coding case material; and the many social workers in the community who completed questionnaires in the prospective and follow up study. Members of the child sexual abuse team at the Hospital for Sick Children gave valuable help and advice at various points in the research and included Anne Elton, Judith Hildebrand, Marianne Tranter, Eileen Vizard, Tilman Furniss, and Malcolm Wiseman.

\section{References}

1 Mrazek PB, Lynch M, Bentovim A. Recognition of child sexual abuse in the United Kingdom. In: Mrazek PB, Kempe CH, eds. Sexually abused children and their families. Oxford: Pergamon Press, 1981.

2 Furniss T, Bingley-Miller L, Bentovim A. Therapeutic approach to sexual abuse. Arch Dis Child 1984;59:865-70.

3 Bentovim A, Elton A, Hildebrand J, Tranter M, Vizard E. Sexual abuse in the family: assessment and treatment. Bristol: John Wright (in press).

4 Finklehor D. Child sexual abuse: new theory and research. New York: Free Press, 1984.

5 Finklehor D, Browne A. The traumatic impact of child sexual abuse. Am $\mathcal{F}$ Orthopsych 1985;55:530-41.

6 Baker T, Duncan S. Child sexual abuse: a study of prevalence in Great Britain. Child Abuse and Neglect 1985;9:457-67.

7 Oliver D. Some studies of families in which children suffer maltreatment. In: Franklin AW, ed. The challenge of child abuse. London: Academic Press, 1977.

8 Bentovim A. First steps towards a systems analysis of severe physical abuse to children in the family. In: First report from Select Committee on Violence in the Family. Vol 3. Appendices. family. In: First report from Select

9 Furness T. Conflict avoiding and conflict regulating patterns in incest and child sexual abuse. Acta Paedopsychiatr 1985;50:6-15.

10 Porter R, ed. Child sexual abuse in the family. London: Tavistock Publications, 1984. (Ciba Foundation Symposium.)

(Accepted 3 September 1987)

\section{How common is allergy to insect bites and what treatment is advised?}

"Insects" are presumed to be arthropods met in the United Kingdom. There is strong evidence that apart from bites by insects that produce visible damage or inject toxic chemicals-for example, bees, wasps, hornets, horseflies, ticks, ants, etc-every visible reaction to an insect bite is caused by an allergic response. The first bite by a gnat or mosquito produces no reaction, not even a histamine flare, but subsequent bites by the same species of insect will produce the classic itchy red papule and sometimes a large bulla. In childhood and occasionally in adults a widespread papular eruption may develop after an apparently single mosquito bite-so called papular urticaria. This widespread reaction eventually subsides so that further bites by the same species provoke no reaction at all. Some insects such as wasps and bees provoke with a single sting quite severe local and even generalised anaphylactic reactions. It is believed that these phenomena are caused by an immune response by the humoral system to the injection of harmless chemicals in the insect's saliva, so that further injections of saliva by the same species of insect provokes an immediate allergic reaction in the form of an urticarial or even anaphylactic response. The loss of this reaction is attributed to the development of blocking antibody. Formation of antibody also accounts for the incubation period of about three weeks after the acquisition of scabies before itching starts, as it usually takes this time to produce humoral antibodies.

Treatment of urticarial insect bites should be with antipruritics such as calamine and crotamiton (Eurax) lotions applied as required until the itch is controlled and the reaction subsides, which usually takes a day or so but occasionally may last for several weeks. Topical remedies containing antihistamines or anaesthetics available without prescription and whose action is primarily anaesthetic should not be used because of the serious risk of allergic contact eczema, often severe. Oral antihistamines may be helpful but are best used to relieve disturbed sleep. Topical steroids are usually unhelpful. Only those patients with severe and widespread papular urticaria may merit a short course of systemic steroids-for example, prednisone 15 $\mathrm{mg}$ daily reducing to zero over a period of a week, provided there is no contraindication to this treatment. If the bites become secondarily infected systemic antibiotic treatment may be necessary, but swabs should first be taken for bacterial culture to ensure that the correct antibiotic is prescribed. Insects living on or in the skin such as lice and scabies obviously merit treatment with appropriate insecticides as do domestic pets harbouring fleas, but those plagued by bites from flying insects may need to use insect repellants on their skin two or three times a day.-ALAN B SHRANK, consultant dermatologist, Shrewsbury. 